\title{
Identifikasi Pertumbuhan Jamur Aspergillus Sp pada Roti Tawar yang Dijual di Kota Padang Berdasarkan Suhu dan Lama Penyimpanan
}

\author{
Dina Khaira Mizana ${ }^{1}$, Netty Suharti ${ }^{2}$, Arni Amir $^{3}$
}

\begin{abstract}
Abstrak
Pangan yang cukup banyak dikonsumsi masyarakat sebagai makanan kudapan di Indonesia adalah roti tawar. Jamur merupakan mikroorganisme utama yang berperan penting dalam proses pembuatan dan pembusukan roti. Aspergillus merupakan kontaminan umum pada berbagai substrat di daerah tropis maupun subtropik. Tujuan penelitian ini adalah membandingkan pertumbuhan jamur Aspergillus sp yang disimpan pada suhu kamar dan suhu di kulkas. Penelitian ini merupakan penelitian eksperimental analitik. Hasil penelitian menunjukan bahwa pertumbuhan jamur pada suhu kamar lebih cepat dibandingkan suhu kulkas. Pada suhu kamar 25C-28C, jamur Aspergillus sp tumbuh mulai hari ke-3 (33,3\%) diikuti pada hari ke-4 (66,7\%), sedangkan pada suhu kulkas (10C-15C) mulai tumbuh pada hari ke-5. Temperatur ini juga berhubungan dengan kelembaban relatif karena semakin tinggi suhu maka kelembaban relatif semakin rendah dan sebaliknya, semakin rendah suhu maka kelembaban relatif akan semakin tinggi. Kesimpulan studi ini ialah terdapat perbedaaan pertumbuhan jamur Aspergillus sp yang disimpan pada suhu kamar dan suhu di kulkas walaupun perbedaannya tidak terlalu besar.
\end{abstract}

Kata kunci: roti tawar, aspergillus sp, suhu, lama penyimpanan

\begin{abstract}
The popular foods consumed by Indonesian citizens is loaves. Fungus is the main microorganism which has the main role in the process of loaves production and decomposition. Aspergillusis the eukaryotes microorganism that has the widest spread in the nature. This worm is also spreading in various substrates in the tropical and sub-tropical areas. The objective of this study was to compare the growth of Aspergillus sp stored in the room temperature and refrigerator temperature This research is analytic experimental. The results of this research showed that the growth of fungus in the room temperature is faster than refrigerator temperature. In the room temperature, the fungus growth starts in the day-3 (33.3\%) that is followed by dy-4 (66.7\%), while the refrigerator temperature (100C-150C) shows that the fungus growth starts on day-5. The temperature is also related to the Relative Humidity (RH), the higher the temperature, so $\mathrm{RH}$ will become lower and vice versa. The foods which store in the low RH will be damaged on the surface side since the fungus, yeast, and certain bacteria. Hence, the fungus on loaves stored in the room temperature will be faster than loaves stored in the refrigerator temperature. There is a difference on the growth of Aspergillus sp stored in the room temperature and refrigerator temperature, even if the difference is not too big.
\end{abstract}

Keywords: fresh bread, aspergillus sp, temperature, prolonged storage

Affiliasi penulis: 1. Pendidikan Dokter FK UNAND (Fakultas Kedokteran Universitas Andalas, 2. Bagian Mikrobiologi FK UNAND, 3. Bagian Biologi FK UNAND

Korespondensi: Dina Khaira Mizana, email:

dinakhairamizana@yahoo.com, Telp: 083182645017

\section{PENDAHULUAN}

Pangan adalah segala sesuatu yang berasal dari sumber hayati dan air, baik yang diolah maupun tidak. Sebagai kebutuhan dasar, pangan merupakan hak asasi setiap rakyat Indonesia, sehingga harus 
senantiasa tersedia cukup setiap waktu, aman, bermutu, bergizi dan beragam dengan harga yang terjangkau oleh daya beli masyarakat. ${ }^{1}$ Dalam proses penyiapan, pengolahan dan pembuatan makanan atau minuman diperlukan suatu sistem pangan yang memberikan perlindungan baik bagi produsen maupun konsumen pangan, serta tidak bertentangan dengan keyakinan masyarakat. Untuk mencapai tujuan tersebut pemerintah telah melakukan berbagai upaya melalui pengaturan, pembinaan dan pengawasan terhadap pangan. ${ }^{1}$

Salah satu contoh pangan yang cukup banyak dikonsumsi masyarakat sebagai makanan kudapan di Indonesia sekarang adalah roti. Pangan ini merupakan makanan manusia yang telah dikenal sejak dulu.Jenis makanan ini biasa dikonsumsi oleh masyarakat dari berbagai belahan dunia. Roti digemari karena rasanya yang lezat disamping nilai gizinya yang baik. Banyak jenis roti yang beredar di pasaran, salah satunya adalah roti tawar yang sering digunakan sebagai menu sarapan pagi sebagian masyarakat Indonesia.

Menurut Kusuma, tepung terigu yang menjadi bahan dasar dalam pembuatan roti tawar mengandung pati dalam jumlah yang relatif tinggi. ${ }^{2}$ Pati ini dapat dihidrolisis menjadi gula sederhana oleh mikroorganisme khususnya jamur, karena gula sederhana merupakan sumber nutrisi utama bagi mikroorganisme tersebut. ${ }^{3}$ Jamur merupakan mikro organisme utama yang berperan penting dalam proses pembuatan dan pembusukan roti. Beberapa jenis jamur yang sering ditemukan pada pembusukan roti adalah Rhizopus stolonifer, Penicillium sp, Mucor sp dan Geotrichum $s p$ serta juga bisa terdapat Aspergillus sp dan lainnya. ${ }^{4}$

Aspergillus merupakan mikroorganisme eukariot, saat ini diakui sebagai salah satu diantara beberapa makhluk hidup yang memiliki daerah penyebaran paling luas serta berlimpah di alam, selain itu jenis kapang ini juga merupakan kontaminan umum pada berbagai substrat di daerah tropis maupun subtropis. ${ }^{5}$ Oleh karena itu, kemungkinan besar banyak jenis Aspergillus juga dapat hidup pada roti tawar.

Jamur Aspergillus $s p$ dapat menghasilkan beberapa mikotoksin. Salah satunya adalah aflatoksin yang paling sering dijumpai pada hasil panen pertanian serta bahan makanan pokok di banyak negara berkembang sehingga mengancam keamanan pangan. Aflatoksin adalah jenis toksin yang bersifat karsinogenik dan hepatotoksik. Manusia dapat terpapar oleh aflatoksin dengan mengkonsumsi makanan yang terkontaminasi oleh toksin hasil dari pertumbuhan jamur ini. Kadang paparan sulit dihindari karena pertumbuhan jamur di dalam makanan sulit untuk dicegah. $^{7}$

\section{METODE}

Penelitian yang bersifat eksperimental ini diawali dengan sterilisasi alat terlebih dahulu, dicuci bersih dan dikeringkan. Alat tersebut disterilkan dalam autoklaf pada suhu 121 'C tekanan 15 psi (pound per square inci) selama 15 menit. Jarum ose disterilkan dengan membakar pada lampu spiritus atau Bunsen.

Roti disimpan pada wadah yang steril yaitu plastik, di masing-masing suhu yakni suhu kulkas $\left(10^{\circ} \mathrm{C}-15^{\circ} \mathrm{C}\right)$ dan suhu kamar $\left(25^{\circ} \mathrm{C}-28^{\circ} \mathrm{C}\right)$. Setiap roti tawar disuir-suir lalu ditanam ke dalam media agar dextrosa Sabouraud kemudian diinkubasi pada suhu $27^{\circ} \mathrm{C}$ selama 3-5 hari. Setelah di inkubasi selama 3-5 hari, jamur yang telah ditanam pada media agar tersebut diperiksa dengan menggunakan mikroskop untuk menentukan jenis jamur yang tumbuh.

Identifikasi jamur Aspergillus dilakukan dengan pengamatan mikromorfologi dan makromorfologi. Pengamatan makromorfologi dengan mengamati warna koloni pada medium agar. Pengamatan mikroskopis meliputi konidia, konidiofor, vesikel, metula dan fialid. Hasil pengamatan makromorfologi dan mikromorfologi digunakan untuk melakukan identifikasi menurut Robert A. Samson dan Ellen S. van Reenen-Hockstra. Hasil yang diperoleh pada penelitian dalam bentuk foto dan dianalisis menggunakan analisis deskripstif.

\section{HASIL}

Penelitian ini dilakukan di laboratorium Mikrobiologi Fakultas Kedokteran Universitas Andalas mengenai identifikasi pertumbuhan jamur Aspergillus $s p$ pada roti tawar yang dijual di kota Padang berdasarkan suhu dan lama penyimpanan. 
Tabel 1. Data pertumbuhan jamur Aspergillus sp pada roti tawar yang Disimpan di Kulkas

\begin{tabular}{|c|c|c|c|c|c|c|c|c|c|c|c|c|c|c|}
\hline \multirow[b]{2}{*}{ Roti } & \multicolumn{14}{|c|}{ Hari } \\
\hline & 1 & 2 & 3 & 4 & 5 & 6 & 7 & 8 & 9 & 10 & 11 & 12 & 13 & 14 \\
\hline $\mathrm{I}$ & - & - & - & - & $\sqrt{ }$ & $\sqrt{ }$ & $\sqrt{ }$ & $\sqrt{ }$ & $\sqrt{ }$ & $\sqrt{ }$ & $\sqrt{ }$ & $\sqrt{ }$ & $\sqrt{ }$ & $\sqrt{ }$ \\
\hline II & - & - & - & - & $\sqrt{ }$ & $\sqrt{ }$ & $\sqrt{ }$ & $\sqrt{ }$ & $\sqrt{ }$ & $\sqrt{ }$ & $\sqrt{ }$ & $\sqrt{ }$ & $\sqrt{ }$ & $\sqrt{ }$ \\
\hline III & - & - & - & - & $\sqrt{ }$ & $\sqrt{ }$ & $\sqrt{ }$ & $\sqrt{ }$ & $\sqrt{ }$ & $\sqrt{ }$ & $\sqrt{ }$ & $\sqrt{ }$ & $\sqrt{ }$ & $\sqrt{ }$ \\
\hline
\end{tabular}

Tabel 2. Data pertumbuhan jamur Aspergillus sp pada roti tawar di suhu kamar

\begin{tabular}{|c|c|c|c|c|c|c|c|c|c|c|c|c|c|c|}
\hline \multirow[b]{2}{*}{ Roti } & \multicolumn{14}{|c|}{ Hari } \\
\hline & 1 & 2 & 3 & 4 & 5 & 6 & 7 & 8 & 9 & 10 & 11 & 12 & 13 & 14 \\
\hline$I$ & - & - & - & $\sqrt{ }$ & $\sqrt{ }$ & $\sqrt{ }$ & $\sqrt{ }$ & $\sqrt{ }$ & $\sqrt{ }$ & $\sqrt{ }$ & $\sqrt{ }$ & $\sqrt{ }$ & $\sqrt{ }$ & $\sqrt{ }$ \\
\hline II & - & - & $\sqrt{ }$ & $\sqrt{ }$ & $\sqrt{ }$ & $\sqrt{ }$ & $\sqrt{ }$ & $\sqrt{ }$ & $\sqrt{ }$ & $\sqrt{ }$ & $\sqrt{ }$ & $\sqrt{ }$ & $\sqrt{ }$ & $\sqrt{ }$ \\
\hline III & - & - & - & $\sqrt{ }$ & $\sqrt{ }$ & $\sqrt{ }$ & $\sqrt{ }$ & $\sqrt{ }$ & $\sqrt{ }$ & $\sqrt{ }$ & $\sqrt{ }$ & $\sqrt{ }$ & $\sqrt{ }$ & $\sqrt{ }$ \\
\hline
\end{tabular}

Roti tawar yang telah berjamur ini kemudian ditanam pada media agar sabouroud dan setelah 3-5 hari diiunkubasi kemudian dilakukan pemeriksaan melalui mikroskop untuk mengidentifikasi jenis jamur yang tumbuh pada roti.Pada pemeriksaan mikroskop dengan 40x pembesaran.

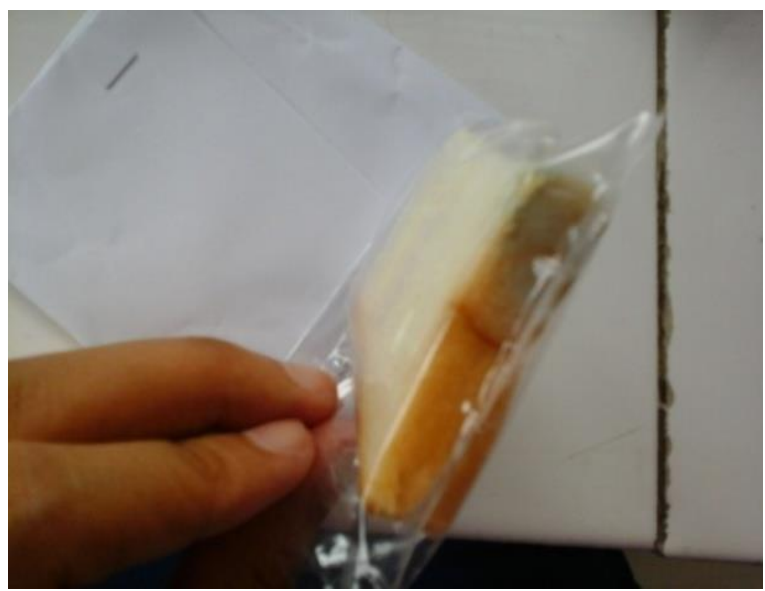

Gambar 1. Gambaran makroskopis roti tawar pada suhu kamar

Pada gambar diatas didapatkan gambaran jamur yang teridentifikasi sebagai jamur Aspergillus $s p$ karena pada gambar dapat ditemukan konidia, konidiofor, vesikel dan fialid yang merupakan bagian dari morfologi jamur Aspergillus sp.

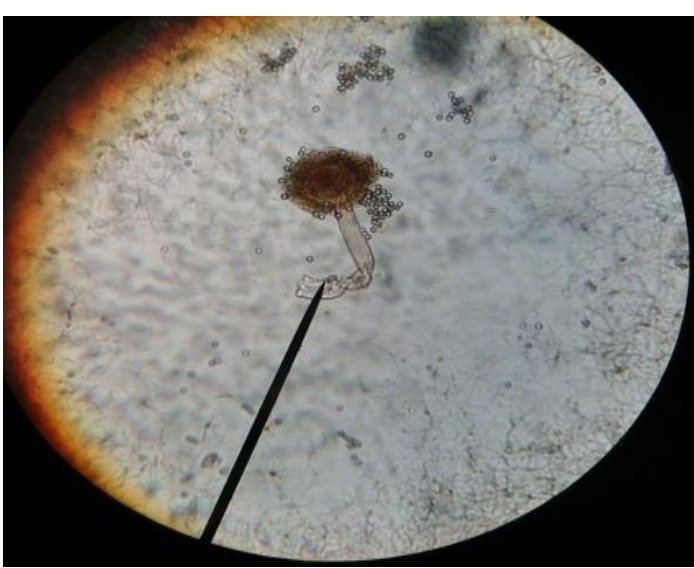

Gambar 2. Gambaran jamur Aspergillus sp pada roti tawar suhu kamar hari ke-4 dengan mikroskop pembesaran $40 x$

Tabel 3. Distribusi frekuensi pertumbuhan jamur Aspergillus sp pada roti tawar

\begin{tabular}{ccccc}
\hline Suhu & Hari ke-3 & Hari ke-4 & Hari ke-5 & Total \\
\cline { 2 - 5 } & \multicolumn{4}{c}{ Persen } \\
\cline { 2 - 5 } Kamar & 33.3 & 67.7 & 100 \\
$\left(25^{\circ} \mathrm{C}-28^{\circ} \mathrm{C}\right)$ & & & 100 & 100 \\
Kulkas & - & - & & \\
$\left(10^{\circ} \mathrm{C}-15^{\circ} \mathrm{C}\right)$ & & & & \\
\hline
\end{tabular}

Pada Tabel 3 diatas dapat dijelaskan bahwa pertumbuhan jamur Aspergillus sp pada roti tawar di suhu kamar hanya $33,3 \%$ pada hari ketiga dan $66,7 \%$ 
tumbuh pada hari keempat, sedangkan penyimpanan pada suhu kulkas $100 \%$ tumbuh pada hari kelima. Jika dibandingkan penyimpanan roti tawar pada suhu kamar dan suhu kulkas terdapat perbedaan walaupun tidak terlalu besar terhadap pertumbuhan jamur, yaitu penyimpanan pada suhu kulkas satu hari lebih lama dibandingkan dengan suhu ruang. Pertumbuhan jamur pada roti tawar yang disimpan pada suhu kulkas terlihat pada penanaman di media agar Sabouraud.

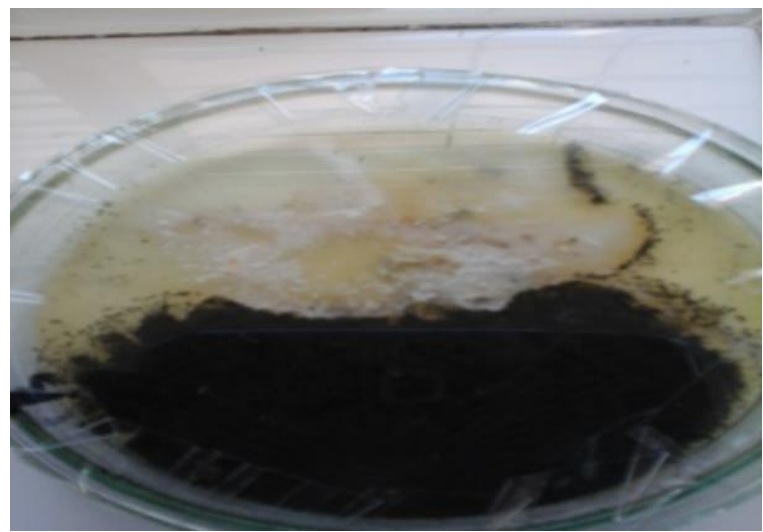

Gambar 3. Gambaran penanaman jamur roti suhu kulkas hari ke-5 pada media Sabouroud dengan diameter $\pm 4 \mathrm{~cm}$

Pada hasil penelitian juga didapatkan bahwa dengan bertambahnya hari penyimpanan, jumlah distribusi pertumbuhan jamur juga semakin meningkat dan menghasilkan berbagai macam perubahan warna pada permukaan roti tawar khususnya pada penyimpanan di suhu kamar. Pada awal pertumbuhan jamur di permukaan roti, warna yang ditimbulkan adalah warna biru, selanjutnya dapat ditemukan warna lain, seperti warna hijau, kuning, dan hitam.

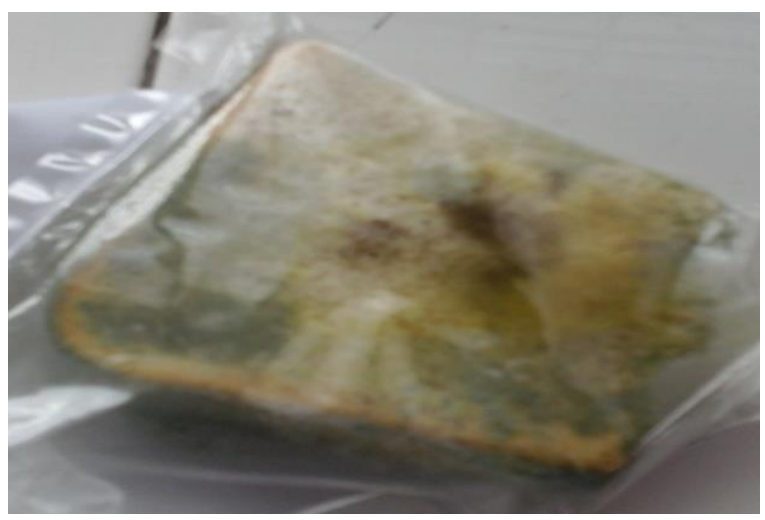

Gambar 4. Gambaran makroskopis roti tawar suhu kamar hari ke-11

\section{PEMBAHASAN}

Penelitian yang dilakukan untuk mengidentifikasi pertumbuhan jamur Aspergillus $s p$ pada tiga buah sampel roti tawar yang dijual di kota Padang dapat dijelaskan bahwa jamur Aspergillus $s p$ sudah tumbuh pada satu roti tawar dari tiga sampel $(33,3 \%)$ pada hari ke-3 dan dua sampel lainnya baru teridentifikasi pada hari ke-4 di suhu kamar $\left(25^{\circ} \mathrm{C}\right.$ $\left.28^{\circ} \mathrm{C}\right)$, sedangkan pada suhu kulkas $\left(10^{\circ} \mathrm{C}-15^{\circ} \mathrm{C}\right)$ jamur baru terlihat tumbuh pada media agar Sabouraud pada hari ke-5 untuk ketiga merek roti tawar. Pada suhu kamar secara kasat mata perubahan warna pada permukaan roti tawar sudah terlihat, sedangkan pada suhu kulkas tidak terdapat perubahan warna di permukaan roti tawar sampai hari ke-14 yang terjadi adalah perubahan tekstur yang menjadi sedikit keras.

Pertumbuhan jamur pada suhu kamar lebih cepat dibandingkan suhu kulkas karena salah satu faktor yang mempengaruhi pertumbuhan jamur adalah suhu. Suhu ini akan mempengaruhi reaksi kimiawi dan reaksi enzimatis pada miroba yang berpengaruh pada pertumbuhan mikroba. Selain itu, suhu juga akan mempengaruhi kecepatan tumbuh pada mikroba. ${ }^{7}$

Rentang suhu untuk pertumbuhan jamur Aspergillus $s p$ yaitu mulai dari suhu kecil dari $20^{\circ} \mathrm{C}$ dan optimum pada suhu $20^{\circ} \mathrm{C}-30^{\circ} \mathrm{C}$. Suhu optimum untuk pertumbuhan jamur Aspergillus sp adalah suhu $20^{\circ} \mathrm{C}$ $30^{\circ} \mathrm{C}{ }^{7}$ hal ini sesuai dengan hasil penelitian yang dilakukan. Pada suhu kamar, yaitu $25-28^{\circ} \mathrm{C}$ jamur pada roti tawar lebih cepat tumbuh dibandingkan dengan suhu kulkas $\left(10^{\circ} \mathrm{C}-15^{\circ} \mathrm{C}\right)$. Temperatur suhu ini juga berhubungan dengan Kelembaban Relatif $(\mathrm{RH})$ karena semakin tinggi suhu maka $\mathrm{RH}$ semakin rendah dan sebaliknya, semakin rendah suhu maka $\mathrm{RH}$ akan semakin tinggi. Bahan pangan yang disimpan pada $\mathrm{RH}$ yang rendah dapat mengalami kerusakan pada permukaannya karena jamur, yeast, dan bakteri tertentu. Pada penelitian yang dilakukan di suhu kamar dimana suhunya lebih tinggi dibandingkan suhu kulkas berarti memiliki $\mathrm{RH}$ yang lebih rendah sehingga menyebabkan pertumbuhan jamur pada roti tawar lebih cepat pada suhu kamar. ${ }^{7}$

Menurut Koswara yang melakukan penelitian pada tahun 2009 salah satu jenis jamur yang sering 
ditemukan dalam roti adalah Aspergillus $s p .{ }^{4}$ Hal yang sama ditemukan pada penelitian ini, yaitu jenis jamur yang teridentifikasi adalah Aspergillus $s p$. Menurut Kusuma, tepung terigu yang menjadi bahan dasar dalam pembuatan roti tawar mengandung pati dalam jumlah yang relatif tinggi. ${ }^{2}$ Pati dapat dihidrolisis menjadi gula-gula sederhana oleh mikroorganisme khususnya jamur karena gula-gula sederhana merupakan sumber nutrisi utama bagi mikroorganisme. $^{3} \mathrm{Hal}$ inilah yang meyebabkan jamur dapat tumbuh pada roti tawar.

Identifikasi jamur Aspergillus sp pada penelitian ini dilakukan dengan pemeriksaan makromorfologi dan mikromorfologi. Pada pemeriksaan makromorfologi didapatkan warna koloni yang tumbuh pada media agar Sabouroud adalah coklat kehitaman dan hitam. Warna koloni yang didapatkan telah sesuai dengan identifikasi jamur Aspergillus sp menurut penelitian Robert A. Samson dan Ellen S. van Reenen-Hockstra pada tahun 1988 dimana koloninya terdiri atas beberapa warna seperti putih, kuning, coklat kekuningan, coklat atau hitam, dan hijau. Warna koloni dari Aspergillus sp ini secara keseluruhan merupakan warna dari konidianya. ${ }^{5}$ Produksi pigmen pada Aspergillus sp sangat dipengaruhi oleh ada atau tidaknya trace element. ${ }^{8}$

Pada pemeriksaan mikromorfologi dengan mikroskop pada pembesaran 400X didapatkan gambaran jamur Aspergillus $s p$ yang sesuai dengan identifikasi menurut Robert A. Samson dan Ellen S. van Reenen-Hockstra dimana pada gambaran yang ditemukan jamur tersebut, yaitu terdiri atas kepala konidia, konidia, fialid, vesikel dan konidiofor. Kepala konodia adalah struktur yang terletak di bagian terminal konidiofor, berbentuk bulat (globose) atau semibulat (subglobose) tersusun atas vesikel, metula (jika ada), fialid dan konidia. Vesikel adalah pembesaran konidiofor pada bagian apeksnya membentuk suatu struktur berbentuk globose, hemisferis, elips atau clavate. konidiofor merupakan suatu struktur tegak lurus yang muncul dari sel kaki dan pada ujungnya menghasilkan kepala konidia. Sebagian besar dari spesies Aspergillus sp memiliki konidiofor tidak bercabang yang masing-masing menghasilkan kepala konidia tunggal. ${ }^{8}$

\section{KESIMPULAN}

Terdapat perbedaaan kecepatan pertumbuhan jamur Aspergillus sp yang disimpan pada suhu kamar dan suhu di kulkas walaupun perbedaannya tidak terlalu besar. Pertumbuhan jamur Aspergillus sp pada roti tawar yang disimpan pada suhu kamar lebih cepat dibandingkan pada roti tawar yang disimpan pada suhu kulkas.

\section{SARAN}

Bagi masyarakat agar tidak mengkonsumsi roti tawar yang disimpan di suhu kamar lebih dari 3 hari dan pada suhu kulkas lebih dari 5 hari, serta roti yang telah mengalami perubahan warna, bau dan tekstur.

\section{DAFTAR PUSTAKA}

1. Direktorat Bina Produksi dan distribus kefarmasian. modul pelatihan pengawasan pangan kabupaten kota. Jakarta: Departemen Kesehatan Republik Indonesia; 2011.

2. Kusuma R. Pengaruh penggunaan cengkeh (Syzygium aromaticum) dan kayu manis (Cinnamomum) sebagai pengawet alami terhadap daya simpan roti manis (skripsi). Bogor: Institut Pertanian Bogor; 2008.

3. Syorayah I, Nuraini D, Chayaya I. Analisis kandungan boraks $\left(\mathrm{Na}_{2} \mathrm{~B}_{4} \mathrm{O}_{7} 10 \mathrm{H}_{2} \mathrm{O}\right)$ pada roti tawar yang bermerek dan tidak bermerek yang dijual di kelurahan Padang Bulan Kota Medan Tahun 2012 (skripsi). Medan: Universitas Sematera Utara; 2012.

4. Koswara S. Teknologi pengolahan roti. [serial online] 2009 (diunduh 17 Februari 2014).Tersedia dari: URL: HYPERLINK http://tekpan.unimus.ac.id/ wpcontent/ uploads/2013/07/Teknologi-Roti-Teoridan-Praktek.pdf.

5. Adriani W. Isolasi dan Identifikasi kapang Aspergillus spp dari kopi (Coffea $s p$ ) bubuk (skripsi). Semarang: Universitas Diponegoro; 2005.

6. Badan POM RI. Pentingnya promosi keamanan pangan di sekolah untuk menyelamatkan generasi penerus. InfoPOM [serial online] 2011 (diunduh 5 November 2013). Tersedia dari: URL: HYPERLINK http://perpustakaan.pom.go.id/KoleksiLainnya/Bule tin\%20Info\%20POM/0611.pdf 
7. Nani R.Diktat Mikrobiologi Pangan. 2010 (diunduh 2 April 2014).Tersedia dari: URL: HYPERLINK http://staff.uny.ac.id/sites/default/files/Diktat\%20Ba b\%201\%20Mikrobiologi\%20Pangan\%20-\%20

Prinsip\%20Mikrobiologi\%20Pa\%E2\%80\%A6.pdf
8. Muzayyin Y. Isolasi dan karakterisasi kapang aspergillus dari roti tawar (skripsi). Semarang: Universitas Diponegoro; 2003. 